$\begin{array}{ll}\text { Research Square } & \text { Preprints are preliminary reports that have not undergone peer review. } \\ \text { They should not be considered conclusive, used to inform clinical practice, } \\ \text { or referenced by the media as validated information. }\end{array}$

\title{
The Effects of the COVID-19 Pandemic on the City Pilots Served by AB InBev Foundation's Global Smart Drinking Goals Initiative
}

Ashley Simons-Rudolph ( $\sim$ Asimons-rudolph@pire.org)

Pacific Institute for Research and Evaluation

Liz Lilliott-González

Pacific Institute for Research and Evaluation

Deborah A. Fisher

Pacific Institute for Research and Evaluation

Christopher L. Ringwalt

Pacific Institute for Research and Evaluation

Research article

Keywords: COVID-19, alcohol use, domestic violence, AB InBev Foundation

Posted Date: September 8th, 2020

DOI: https://doi.org/10.21203/rs.3.rs-60028/v1

License: (c) (1) This work is licensed under a Creative Commons Attribution 4.0 International License. Read Full License 


\section{Abstract}

\section{Background}

The COVID-19 pandemic has affected many aspects of global health, including efforts to curb harmful drinking. Very little is known about the effects of a prolonged disaster like this pandemic on alcohol consumption, misuse, and related harms, and on ongoing interventions designed to prevent or mitigate these harms.

\section{Methods}

We collected information from key informants in community coalitions in each of five City Pilots funded by the AB InBev Foundation that are implementing prevention and early intervention strategies to reduce harmful drinking. Key informants reported how the pandemic has affected alcohol sales and consumption in their communities, as well as alcohol-related harms such as interpersonal violence and drink driving.

Results

We found that alcohol production has slowed and that sales of alcohol have uniformly decreased. However, the effects of local regulations on alcohol sales in on- and off-premise establishments have been uneven. Early reports suggest that home-based drinking has decreased during the pandemic, binge drinking is still problematic, and that while the prevalence of drink driving is greatly reduced, domestic violence has increased. We also report measures taken by the $A B$ InBev Foundation to support the City Pilots' efforts to combat the pandemic, which include transitioning inperson prevention strategies to online delivery where feasible, and the reorientation of the AB InBev Foundation's Community Fund to support local efforts to combat the pandemic.

\section{Conclusions}

While it presents considerable challenges for ongoing prevention efforts that depend on interpersonal contact, the Community Fund appeared to have a positive effect on building community coalitions, bringing new stakeholders to the table, and providing the opportunity for the coalitions to enhance their visibility and reputations in the communities they serve.

\section{Background}

The effects-or at least the threat-of the current coronavirus disease (COVID-19) pandemic are now being felt in every country throughout the world. As of this writing, these effects have been experienced most greatly by wealthier countries including China, Italy, Spain, and the United States. The pandemic has also invaded less developed nations, such as Brazil, whose economies and health care systems are much more fragile and where its consequences are likely to be even more severe. While the true nature and extent of these effects on physical morbidity and psychosocial distress are not yet known, one area of growing concern is the pandemic's implications for the misuse of alcohol and alcohol-related harms. In the United States, analyses of social media suggest that people are demonstrating a greater interest in alcohol than health care; online engagement with 300 alcoholic beverage brands increased by over $325 \%$ compared to a year ago, whereas engagement with websites related to health care rose only $130 \%$. Further, the Nielsen company reported that, in comparison to this time in 2019 , purchases of spirits, wine, and beer (excluding flavored malt beverages and cider) rose by $75 \%, 66 \%$, and $34 \%$, respectively [1]. An increase in alcohol consumption is likely to be associated with an increase in alcohol-related harms such as domestic violence and drink driving. Significant increases in alcohol sales have been noted in Russia, which has generated concerns there about potential spikes in drinking and domestic violence [2]. A 30\% rise in domestic violence has been documented in France [3] and is thought to be fueled by anxiety and the isolation generated by social distancing and sequestration orders [2, 4]. Concern about the potential for alcoholrelated violence has led the World Health Organization (WHO) to call for heightened vigilance in the enforcement of regulations concerning alcohol access [5]. While increased alcohol consumption has typically been associated with drink driving [6], much of the current concern has centered on interpersonal and domestic violence.

The scientific literature concerning the effects of natural and man-made disasters on alcohol consumption and abuse has generally, but not consistently, revealed a positive relationship [7]. Examining the sequelae of the 2001 terrorist attack on the World Trade Center, two related investigations reported increases in alcohol consumption, binge drinking, and alcohol dependence one year post-disaster [8, 9]. Increased drinking and binge drinking have also been observed in the United States in the wake of two hurricanes, Katrina and Rita [10]. On the other hand, an investigation of the effects of ten natural disasters on subsequent alcohol use found no increases in cases of alcohol use disorders post-disaster [11]. Note that several characteristics of these disasters and their effects on alcohol use and misuse differ from the present pandemic. Although the effects of these disasters lingered to varying degrees, each of them was of relatively short duration as an event, none required that people isolate themselves, and the studies of each assessed alcohol consumption in the aftermath-as opposed to the midst-of the event. Additionally, none of these events were associated with curtailing alcohol retail access.

Very little is thus known about the effects of prolonged natural disasters such as the COVID-19 pandemic on alcohol consumption, misuse, and related harms during the disaster itself. We could find only one study that addressed this question, and reported that in a sample of adults in Poland, $16 \%$ reported drinking less whereas $14 \%$ drank more [12]. However, it seems reasonable to suggest that conditions known to promote alcohol misuse 
-for example, the loss of social and economic supports, social isolation, stress, and grief-are likely to promote alcohol misuse [13]. Further, because sequestration orders may increase alcohol consumption at home and thus away from violence-related controls inherent in social drinking contexts, the potential for domestic violence is of particular concern [14], and some reports are emerging of significant increases worldwide [15]. On the other hand, declines in the presence and density of cars on the road would seem to also attenuate the prevalence of both driving under the influence (DUI) and crashes attributable to alcohol use. Reductions in access to alcohol in both on- and off-premise establishments that have been shuttered by governmental regulation may reduce over-consumption.

We also know very little about how the current pandemic affects ongoing community-based efforts to prevent harms related to adult alcohol use. It seems likely, however, that strategies that depend on interpersonal proximity between health care and prevention providers and the general public will be curtailed to ensure their mutual safety. We also know very little about the effect of COVID-19 on efforts to prevent alcohol use among minors. Substance use prevention targeting youth has traditionally been delivered in school settings, and its success has been heavily dependent on utilizing their now empty classrooms to implement role plays and other interactive activities dependent on students' physical proximity to one another [16]. Further, in anticipation of the eventual relaxation of sequestration regulations, opportunities to train servers in the prevention of youth access to alcohol by carding of young-appearing patrons of bars and convenience stores are attenuated. Efforts to train servers in the promotion responsible beverage service [17] are disrupted. Medical personnel may be unavailable to conduct screenings and brief interventions (SBI) for alcohol misuse [18]. Further, the medical workforce already trained in the delivery of prevention services as a key component of their practice may not return to their prior employment once businesses are reopened, and new staff will need to be trained. Media campaigns designed to support any existing prevention efforts are likely to be overshadowed by news related to the pandemic and its effects [13].

The purpose of this manuscript is to explore the effects of the pandemic, as reported by local media, in five City Pilots that the AB InBev Foundation is supporting as part of its Global Smart Drinking Goals (GSDG) initiative. The AB InBev Foundation was created by the AB InBev Company, the world's largest brewery, to reduce harmful drinking globally by identifying effective, evidence-based programs and policies for public-private partnerships that are designed to advance positive social and behavior change [19]. The GSDG initiative includes a set of programs and initiatives designed to reduce alcohol-related harms in five cities: Leuven, Belgium; Johannesburg, South Africa; Brasilia, Brazil; Zacatecas, Mexico; and Columbus, Ohio. Each City Pilot contains a Foundation-sponsored community coalition, the purpose of which is to select and provide support for the implementation of evidence-based prevention strategies targeting various manifestations of harmful alcohol use, including drink driving, binge drinking, and underage drinking [20]. These five City Pilots provide a unique opportunity in which to examine the effects of the COVID-19 pandemic on the alcohol landscape. We also describe how the pandemic is affecting the operations of the community coalitions developed to realize the mission of the GSDG in the City Pilots, as well as the activities they have implemented with the Foundation's support. We conclude with a discussion of the lessons learned from our exploration of the effects of the pandemic in the City Pilots, together with recommendations for future practice related to the prevention of alcohol-related harms within the context of prolonged disasters like this pandemic.

\section{Methods}

In mid-April of 2020 the AB InBev Foundation sent a request to its staff stationed in five of its six City Pilots to complete a brief unstructured questionnaire (available from the first author upon request). We asked local Foundation staff to report how the coronavirus has affected their communities regarding alcohol production, distribution, sales, and consumption, as well as alcohol-related harms such as alcohol dependence, interpersonal violence, and drink driving. They also reported the effects of the pandemic on the operations of their steering committee (SteerCo). Specifically, they specified how the various projects or programs that it was sponsoring or in which it was involved were being adapted to meet the exigencies of local sequestration orders. If any of their programs were suspended, we asked them what plans there were to restart them once these orders were lifted. In addition, we asked the staff to conduct a media scan for, and to provide a summary of, stories related to the local impact of COVID-19 on the alcohol environment.

Finally, staff were asked if they intended to request that the Foundation make use of a "Community Fund" established by the Foundation that offered up to a total of $\$ 50,000$ for new projects in each City Pilot designed to mitigate the pandemic's effects on the local population and address the salient public health needs of the community. Examples of ways that funds could be used included the procurement of medical supplies and equipment and the development and delivery of training for health care providers concerning the prevention and control of COVID-19. The Foundation also asked the local SteerCos to specify the pertinence of the support they requested for the prevention or treatment of alcohol-related harms.

The information reported here is comprised of reports covering the period from the advent of the pandemic in each City Pilot through mid-May 2020.

\section{Results}

Impact of the pandemic on the local manufacture, distribution, and consumption of alcohol and alcohol-related harms per media coverage

Brasilia. In mid-March the government of the federal district, the area within Brasilia containing the three communities constituting the intervention site, mandated that bars, liquor stores, and restaurants close to the general public, but they were allowed to continue home delivery services. However, we know anecdotally that compliance with this regulation was limited, particularly as the President of Brazil made a speech dismissing the importance of sequestration policies, which immediately and substantially decreased social distancing practices. The President of the Brazilian 
Association of Studies on Alcohol and Substance Abuse did warn, however, of the risk of increased alcohol consumption during the pandemic [21]. Further, the Panamerican Health Association rebutted rumors that alcohol consumption might reduce the probability of contracting the virus [22]. The local beer manufacturer noted significant losses in sales in bars and restaurants, most of which remain closed. Altogether, the Brazilian Beverage Association reported that revenue from alcohol beverages nationwide decreased by $50 \%$ in the second half of March. That said, there was a significant increase in direct sales of alcohol to households, although they represented less than $1 \%$ of total alcohol consumption prior to the pandemic. Indeed, there is little evidence of any increase in alcohol consumption;

Reports of alcohol-related harms were noted, and community pilot sites described the harms most salient to their locality. At least one news story warned of the danger of an increase in interpersonal violence as a result of pandemic-related restrictions on movement [23]. Further, reports of gender-based violence increased $45 \%$ relative to last year in the nearby province of Sao Paulo [24]. While no information is available concerning the incidence of drink driving in Brazil, the use of breathalyzers to detect drink driving has stopped because of the lack of personal protective equipment for law enforcement officers and, thus, the prevalence of drink driving is unknown.

In Columbus, local reports of the effects of the pandemic on alcohol sales and consumption varied considerably. One local distributor reported a significant decrease in sales due to the closing of restaurants and bars and the cancellation of sports events and music festivals. There is also anecdotal evidence that the closing of colleges in the Columbus area has resulted in reductions of binge drinking. However, restaurants with liquor licenses that prepare takeout meals can now sell up to two prepackaged drinks with each meal sold, and businesses with existing liquor permits may sell and now deliver alcohol. Outdoor patios serving alcohol re-opened May 15, 2020, with flagrant violations of social distancing [25].

As in Brasilia, early evidence suggests that alcohol-related harms outside the home (e.g., drink driving) are decreasing, while harms inside the home (e.g., domestic violence) increase. In the city, sequestration orders have greatly diminished the number of drivers and the length of their trips, which have had a commensurate decrease of $46 \%$ from 2019 to 2020 in citations for drink driving, according to conversations between the City Pilot and the Columbus city police. The number of these citations has also been reduced by a law enforcement policy that during the pandemic officers should avoid enforcing minor violations to prevent unnecessary contacts with the public. In Mexico, we were advised that law enforcement first detects a drink driver by placing one's head in the car window and inhaling. Indeed, police halted the use of these traditional methods and breathalyzers altogether. Columbus also noted an increase in homicides attributable to domestic violence [26].

Johannesburg. In mid-March the government of South Africa imposed evening closing hours on restaurants, clubs, and off-premise establishments licensed to sell liquor. A week later the government completely banned the sale of all alcohol, and further prohibited consideration to grant new liquor licenses for special events. In so doing the government enacted some of the most stringent regulations of any nation in the world [4]. In response, some bars and restaurants called for the alcohol ban to be lifted [27]. At least one non-governmental organization (NGO), the South African Drug Policy Initiative, expressed concern that the ban on alcohol sales may harm individuals with alcohol dependency [28]. Plans to maintain social distancing while reinstating alcohol sales have been met with public outcry [29]. There was local anecdotal evidence of home brewing (which has led to at least one death in the country) [30], illicit alcohol sales, and alcohol stockpiling [31], all of which raised concerns about the utility of the ban on alcohol sales and the potential for binge drinking. In Alexandra, an impoverished township within Johannesburg that constitutes the primary focus of the City Pilot, some residents have continued to drink in public.

Generally speaking, prohibitions against alcohol sales, coupled with vigorous and visible law enforcement, have contributed to declines in reported crimes [32], and both interpersonal [33] and gender-based [34] violence. However, NGOs in South Africa that would normally serve victims of domestic violence are unable to do so as they are not considered an essential service by the governing authorities. Significant reductions in drink driving crashes have led to calls to regulate alcohol consumption once the pandemic recedes, and President Cyril Ramaphosa said that alcohol was "a hindrance to the fight against coronavirus" [4]. The premier of Gauteng Province, in which the Johannesburg City Pilot is located, expressed his concern about the negative social impacts caused by the consumption of alcohol. "South Africans drink too much, just too much, and it causes accidents and fights. Our hospitals are reporting they no longer have people arriving there with stab wounds, gunshot wounds and wounds sustained in motor vehicle accidents. We must find ways to deal with the negative impacts of alcohol in our society" [35].

Leuven. The federal government of Belgium closed all bars, restaurants, and non-essential businesses in mid-March. There have been only a few reports of bars that have remained open illegally. However, alcohol continues to be available in supermarkets. At the beginning of the outbreak, there were media reports that people were crowding into bars for "lockdown parties" prior to their anticipated closing. Data collected from smartphones suggest that most people have respected lockdown regulations. There has been local speculation that alcohol consumption would increase at home as a result of the lockdown, and that residents would engage in online "happy hours" and "aperos" (an abbreviation of "aperitifs"). However, the City Pilot reports that preliminary results of a study conducted by Katholieke Universiteit Leuven, the local university, have indicated that overall alcohol consumption has not increased, although the study did identify two high-risk groups: employees working at home instead of at their office and those temporarily laid off by the shuttering of local businesses. The study attributed this increase to the use of alcohol in response to negative emotions such as stress and anxiety that are linked to the crisis. Further, local reports of the number of people who "struggle with alcohol" have increased. It is believed that this increase may be linked to alcohol consumption. Local police have informed the public that traffic controls remain in place, and a truck driver has been arrested for drink driving [36]. 
Zacatecas. In late March, the government of Mexico decreed a health emergency and suspended all non-essential activities, which included alcohol production. The distribution and sale of alcoholic beverages, as well as the operation of bars and clubs where alcohol was sold and consumed were restricted by the state governments and Mexicans complained of a national beer crisis [37]. Those that failed to comply were threatened with a revocation of their permits to sell alcohol, and distributors who transported alcohol to private homes were subject to fines [38]. The government also sponsored a "National Campaign of Healthy Distance" that warned citizens against all private and public social gatherings. These included festivals at which alcohol was customarily consumed, such as the annual Fiesta de Jerez. However, restaurants were informed that they could continue to operate at $50 \%$ capacity and to sell alcohol, if they had an existing liquor license. In Mexico, municipal governments can create and enforce their own restrictions. For example, in Guadalupe, one of the communities participating in the City Pilot project, hours of sale were restricted at first to 10 p.m. (statewide) and then further restricted to 8 p.m. following complaints about aberrant behavior in the streets. There is anecdotal evidence that the public initially responded to reductions in the accessibility of beer with a temporary surge in purchases. Alcohol sales taxes were also halted. Stories are emerging of deaths due to tainted, home-brewed alcohol [39].

It has been reported that the prevalence of DUI in the center of Zacatecas has increased, particularly among drivers who consume alcohol in their cars [40]. In May, the State announced and enforced a "no circulation" regulation designed to enforce sequestration decrees by restricting driving to a limited number of days per week based on the final numerals of vehicles' license plates and to prevent any driving whatsoever between the hours of 11:00 p.m. and 8:00 a.m. Police officers have been instructed to identify drunk drivers, and to administer fines of $\$ 450$ to those who fail breathalyzer tests [41].

Shuttered to production, the local distributor in Zacatecas donated personal protective equipment (PPE) made from unused plastic bottles and alcohol extracted from the production of its non-alcoholic beer to the public health institute for distribution to the community [42].

Regarding interpersonal violence, the state of Zacatecas has reported over 2500 cases of family violence that have targeted women; in almost twothirds of these cases the aggressors have been their spouses. Of these cases, almost half have been in the form of emotional violence, and an additional third have been physical in nature. Altogether, reports of family violence have increased by one-quarter since 2019 according to the SubSecretary for Crime Prevention of the State. The temporality between COVID-19 and femicide is concerning as advocates consider the long-term impacts of this wave of violence [43].

\section{Impact of the pandemic on the programs sponsored and the SteerCos' response}

Altogether, plans submitted by the five SteerCos to, and approved by, the Foundation prior to the pandemic included a total of 37 interventions to be implemented in 2020. Of these, 10 are continuing without interruption, 14 have been suspended with the expectation that they might be continued once the pandemic subsides sufficiently, and the residual (13) have been halted altogether pending review in 2021 . With the availability of the Foundation's community fund (described above), SteerCos in Johannesburg, Zacatecas, Columbus, and Leuven pivoted rapidly from primarily focusing on reducing alcohol-related harms to considering how the fund might be used to mitigate the effects of the pandemic in their communities.

Meanwhile, in Brasilia, SBI and responsible beverage service (RBS) trainings are being adapted for delivery through online platforms. Consideration is being given to how to respond to increased reports of gender-based violence and to car crashes attributable to delivery service employees. In addition, the SteerCo is providing mental health support to public health workers, supporting the prevention of gender-based violence, and addressing underage drinking by providing an online service for students at home who are isolated by the pandemic.

Columbus. Electronic screening and brief intervention (E-SBI) continues to be available at and supported by several post-secondary institutions in the Columbus area, but student participation is voluntary. Our key informants in the City Pilot report that plans to make the course mandatory for firstyear students are likely to be suspended. Plans continue to develop an RBS program for servers that will focus on compliance with applicable rules and regulations. Two initiatives were suspended, namely work on developing ignition interlocks for repeat drink driving offenders, and a social marketing campaign designed to support and promote the SteerCo's purchase of a blood alcohol concentration (BAC) truck which enables police to measure drivers' BAC at the site of a crash. That said, the use of the BAC truck is likely to be delayed due to cutbacks in the law enforcement personnel who have been trained to operate it.

In Columbus, the SteerCo applied and was approved for AB InBev Foundation's Community Fund to prepare health and safety bags to be distributed to homeless individuals in shelters, camps, and other locations. Bags will contain the items necessary to avoid infection and encourage harm reduction such as hand sanitizer, masks, first aid kits, sunscreen, and resource material for access to alcohol-, drug-, and mental health-related issues. A screening, brief intervention, and referral to drug treatment (SBIRT) will be offered by a community partner to interested individuals at the points of contact.

Johannesburg. In partnership with the SteerCo, the local AB InBev beer manufacturer, South African Breweries, has pledged to produce 100 thousand liters of alcohol as the basis for sanitizers, as well as to recycle plastic from beer crates to make 100,000 masks to be donated to health care workers. Many of the initiatives planned pre-pandemic by the SteerCo are at least temporarily on hold. The implementation of SBI is suspended, and there are concerns both about the well-being of the health care workers responsible for administering it, and the willingness of the public to visit health care facilities to be screened while the pandemic remains a threat. However, there are plans to finalize training materials and resume operations post- 
lockdown. Plans were being laid to complete the design of the RBS training and to identify an implementation partner. Regarding RBS, the SteerCo found that a design workshop intended to facilitate planning for server training was not as effective as previous in-person meetings, and thus planning for this intervention will be delayed. Of further concern to the implementation of RBS post-pandemic, the SteerCo is aware that some taverns may never reopen, and that the current liquor black market may persist once sequestration orders are lifted. In addition, there is growing hostility between the government and associations of liquor traders attributable to the continued ban on liquor sales, which may impede engaging the liquor outlets that do reopen. The government is investigating tax relief for the liquor industry to support its emergence from the pandemic. The SteerCo is also seeking an implementation partner for a violence prevention program and may prioritize it post-lockdown because of concerns about increases in gender-based violence. Evidentiary breathalyzer alcohol testing through the police department's Alcohol Evidence Center, donated by the SteerCo, has also been suspended, as has an accompanying promotional campaign and a plan to build a database related to drink driving. However, both initiatives are expected to be revived post-lockdown.

In Johannesburg, the SteerCo applied for and received support from the AB InBev Foundation's Community Fund to support three initiatives. The first initiative seeks to prevent binge drinking and violence by purchasing five radio slots on a local FM radio station that include content related to understanding the COVID-19 pandemic and adhering to lockdown regulations and the ban on purchasing liquor, as well as preventing violence. The second of these initiatives would provide PPE to health workers and law enforcement working in 15 clinics and in the Alexandra community, which was specifically requested by the Johannesburg police chief. The last initiative would provide 500 hygiene and nutrition packages to needy and vulnerable families in the township.

Leuven. Since the advent of the city's lockdown in mid-March, the work of the SteerCo members has changed dramatically, with a new focus on managing the crises by supporting the immediate needs of those who are affected (including bars and restaurants) and drafting a recovery strategy to be put in place once the lockdown is lifted. Regarding the delivery of SBI, the general practitioners (GPs) who have traditionally delivered the intervention have become more important than ever because the crisis has generated a high level of trust in the city's health care system. The SteerCo believes that their trustworthiness will increase patients' willingness to be screened for misuse of alcohol as a coping mechanism related to the lockdown. The SteerCo's plans for reviving RBS are less clear given that local bars and taverns will be focused on economic survival, which will increase challenges related to recruiting bar owners and managers interested in RBS training for their staff. On the other hand, increased attention to matters related to the public's health may support these recruitment efforts. That is, tavern owners may recognize the importance of preventing their customers from excessive drinking to ensure the maintenance of appropriate social distance. If so, RBS will be integral to the city's recovery because "smart drinking will become an integral part of social drinking." Plans for the development and implementation of prevention efforts targeting alcohol-related violence and youth alcohol consumption have been indefinitely delayed.

The AB InBev Foundation approved Leuven's request for a print and social media campaign with an attendant evaluation for "What's your new happy hour?" This campaign contradicts the premise that new socially distant gatherings must be centered around alcohol and seeks to promote alcoholfree alternatives such as online meetings, pavement visits (going to a friend's house and staying outside on the sidewalk, respecting the $1.5 \mathrm{~m}$ social distancing rule), and garden talks (neighbors gathering in their own garden and talking over their fence or hedge).

Zacatecas. SteerCo communications continue as normal, with planning discussions occurring among key partners and the suspension of larger more formal events until it is safe to gather. Several programs sponsored by the SteerCo have been suspended due to the constraints that the government imposed on social gatherings. These included SBI as implemented both in school settings and as designed for adults attending primary care health centers. Even through a number of medical providers and staff have been trained in SBI and medical providers remain open, and amid reports of increased alcohol use occurring, very little screening is occurring during the pandemic. Both programs are expected to resume once the pandemic recedes sufficiently, and there is a possibility that the delivery of SBI may move to an online format such as "Chatbox." Other programs that have come to a halt include Empresas que se Cuidan (Businesses that Care), implemented in several area companies, as well as communication and marketing (in support of all interventions), which are expected to be revived, albeit in a somewhat abbreviated form. Still other programs were curtailed but not halted, including the SteerCo's road safety initiative, which should continue post-pandemic and is likely to include a suggestion made by the Foundation's program officer that the licenses of drivers arrested for DUI be temporarily suspended. The Zacatecas SteerCo is also considering developing a program to respond to alcohol-related violence, in collaboration with the State's Sub-Secretary for Crime Prevention.

In Zacatecas, the Governor and the Secretary of Health appealed to the AB InBev Foundation for $\$ 50,000$ to purchase PPE for health care workers in one large or two small hospitals, stating that existing supplies were inadequate. The request referenced a newspaper article stating that Latin America could become the greatest victim of the pandemic [44]. The PPE itemized list included masks, overalls, safety glasses, thermometers, and sanitary gloves, as well as endotracheal tubes, catheters, and electrocardiogram equipment. The request referenced the importance of strengthening the health care system so that at the pandemic's conclusion key Foundation-sponsored programs in Zacatecas could be expeditiously restarted. The Foundation approved this request [45], and Zacatecas concluded that supporting the purchase of PPE "demonstrate(ed) the AB InBev Foundation's commitment to Zacatecan society and its authorities."

\section{Impact of the pandemic on the SteerCos' functioning}

Prior to COVID-19, the focus of SteerCos was on developing and supporting interventions designed to reduce alcohol misuse-specifically drinking by underage persons and pregnant women, binge drinking, and impaired driving-and the harms associated with alcohol use. Within the last several

Page 6/12 
months, as directed by the AB InBev Foundation, the SteerCos' primary purpose has shifted from supporting all 37 interventions in progress prior to the advent of the pandemic to focusing on the limited number that remained active and monitoring the ongoing effects of the pandemic in their communities.

As of the beginning of March, all prevention activities of the City Pilot in Brasilia were suspended, and the leadership focused on developing a new workplan for the year to accommodate a $50 \%$ cut in its budget, which was approved by a virtual meeting of the SteerCo. In Columbus, SteerCo business continued as usual, although regularly scheduled monthly meetings quickly transitioned from in-person to videoconference. In Johannesburg, SteerCo meetings have been suspended for the duration of the lockdown and replaced by virtual meetings. Some public officials have been inaccessible or unavailable, either because they lack access to a work computer or are preoccupied with combatting the pandemic as law enforcers or health care workers. One implementation contractor is temporarily using its facilities for COVID-19 screening and is thus unavailable to administer SBI. During this period, the SteerCo is particularly sensitive to the need to protect the health of its members and thus continue and sustain the project. In Leuven, due to the coronavirus, the SteerCo has replaced in-person meetings with videoconferences. While communications among SteerCo members originally decreased following the lockdown, they have now substantially increased, and the Coordinator reports that "there is a closer alliance and willingness to cooperate. The feeling that 'we're in this together' and 'we have to help each other' is strongly present." In Zacatecas, as in the other sites, the SteerCo adapted quickly to communicating online. A strong partnership with the local beer manufacturers' partner prevention program allowed for good communication about how to best assign now limited resources between funders. Through the social capital built upon strong ties to community leaders and generated by its application for Community Funds, the SteerCo was able to add an additional stakeholder, the Ministry of Migrants for the State of Zacatecas.

\section{Discussion}

As illustrated by the information provided by key City Pilot staff involved in the AB InBev Foundation's Global Smart Drinking Goals (GSDG) initiative and their scan of local and regional media, the COVID-19 pandemic has had a substantial effect on the alcohol environment of the cities served. While alcohol accessibility has greatly decreased in all the cities served by the GSDG's SteerCos, reports of how alcohol consumption has been affected in each vary considerably. Also varying are the contexts in which alcohol is now being consumed, such as parked cars in Zacatecas. Similarly, reports of domestic violence, which have widely been expected to spike in response to sequestration orders, differ markedly by site. These various estimates point to the need to continue to closely monitor and conduct ongoing needs assessments of alcohol misuse and related harms throughout the duration of the pandemic in order to intervene quickly to mitigate their effects. We recognize that this will be challenging at a time when public health efforts are almost exclusively devoted to developing measures to combat the COVID-19 itself, but the work is urgent as alcohol misuse is likely to exacerbate the pandemic's effects.

The information collected from the five sites reveals greatly altered operations and activities of the SteerCos established in each. The prevention and early intervention services offered by the SteerCos with Foundation support have been attenuated, and many have been suspended altogether until the pandemic recedes sufficiently. Even so, the Foundation and its City Pilot SteerCos have demonstrated considerable capacity and creativity to adapt to a radically changed environment in which the implementation of many traditional prevention-related strategies are no longer feasible.

First, as in much of the world, in-person gatherings have been replaced by virtual meetings. What remains to be seen is whether such meetings constitute an effective substitute, and whether and to what extent they can be maintained once sequestration orders are lifted, especially in City Pilots in which travel is prohibitively time-consuming. Attention should be paid to how virtual meetings can best be conducted, and how meeting productivity is positively or adversely affected once SteerCo members settle into the routine of what may become a new normal.

Consideration should also be given to whether and how prevention strategies can be successfully adapted to web-based formats. There are a variety of precedents to doing so, including electronic versions of SBI [46], RBS [47], and binge drinking prevention by college students [48]. This literature should be systematically reviewed to determine which prevention strategies have demonstrated effectiveness when adapted to online delivery, and the strength of the pertinent evidence. Attention should also be given to how these programs were successfully adapted, and whether their subsequent reach and penetration were sufficient to warrant their implementation. Even in cases in which the effects noted in their original, in-person formats are attenuated, their reach and penetration may increase sufficiently that they should be considered, particularly as their implementation costs may well decrease substantially. Electronic versions of prevention strategies of interest also have the potential to facilitate the targeting of vulnerable indicated and selective populations, thus avoiding some of the inefficiencies of universal prevention approaches. But crucial questions remain to be answered. For example, do the populations targeted have access to the hardware and networks required to access a given e-prevention strategy? If online services are available, is it likely that the adapted interventions will have sufficient acceptability for widespread use? What measures will need to be taken to promote the uptake of the strategy by the populations targeted, as well as their continued involvement for its duration?

The pandemic provides opportunities for the SteerCos to engender goodwill in their local contexts by supporting regulations promulgated to protect the public. Doing so has the added benefit of placing alcohol prevention within the mainstream of public health at a time when its importance is elevated. For example, media campaigns could reinforce the importance of sequestration orders, stress the importance of wearing masks and maintaining social distance, and address myths about the protective characteristics of alcohol. Such campaigns could also warn local residents of the dangers of alcohol misuse, particularly as it may be linked with an uptick in both physical and emotional domestic violence and publicize

Page $7 / 12$ 
available services such as safe shelters. In cities where local authorities are contemplating maintaining some degree of restrictions on alcohol availability post-pandemic to reduce related harms, particularly at fiestas or sporting events, SteerCos should consider actively supporting these measures (or at least not opposing them), even if this position places them at odds with local businesses that sell alcohol. It is clearly important for local coalitions that seek to mitigate alcohol-related harms to be, and to be perceived as, independent of the alcohol industry.

In addition to garnering goodwill from the broader local community, SteerCos' collaborative efforts to support public health during the pandemic may benefit them by bringing them together with new community partners. SteerCos may find that organizations with which they have not previously worked because of real or perceived differences in goals and approaches can now collaborate successfully against the common threat of the novel coronavirus. To the extent that these new joint endeavors create opportunities to dispel misconceptions and enhance mutual respect, SteerCos may find that this disruption to their original mission has laid the groundwork for an expanded base of support among community organizations in the post-COVID-19 environment.

In response to the exigencies of the pandemic, the AB InBev Foundation and its City Pilot-based SteerCos quickly adopted a variety of measures that could serve as an exemplar to the substance use prevention community. First, it quickly suspended the implementation of a number of prevention strategies that depended on interpersonal contact and could not readily be adapted to a web-based format. Second, it repurposed its "community fund," which was originally intended to support local incubators for promising practices targeting alcohol-related harms that lacked evidence of effectiveness. As reconceptualized, the fund was used to support applications by the SteerCos for small projects designed to mitigate the effects of the pandemic, several of which are described above. These projects serve a variety of purposes, which include keeping the SteerCos engaged and involved in the development and implementation of prevention activities, and reinforcing relationships with the local governmental authorities who were required to provide letters of support for the applications. Perhaps most important, the projects funded responded to pressing community needs including PPE for beleaguered health care workers and law enforcement officers, some of whom will be involved in administering post-pandemic prevention programs such as SBI. Still other funded activities, however, included media outreach into the community to disseminate key information pertinent to the pandemic, as well as hygiene and nutrition packages for vulnerable families. Whereas these latter initiatives are unrelated to alcohol prevention, they may be expected to establish and enhance the reputation of the SteerCos in the communities they serve, and thus facilitate future prevention efforts.

Several methodological issues should be kept in mind in interpreting the results of this manuscript. First, it was developed a scant ten weeks into a pandemic that may endure much longer, at the conclusion of which the alcohol-related prevention landscape may have changed beyond recognition. Second, the media referenced to describe the effects of the pandemic should not be considered inclusive or even representative, since it depended on search terms that applied primarily to print media in communities where relevant information may flow from multiple sources. Third, each country was at a different stage of the pandemic at the time of data collection, thus the extent to which stay-at-home orders and restrictions on alcohol use and consumption may vary as a result. Fourth, the key informants who completed the surveys on which the manuscript is based were all employed by the $A B$ InBev Foundation, and thus may have brought pro-Foundation biases to bear on their responses. However, their knowledge as residents of the City Pilots placed them in a unique position to report the pandemic's effects in a number of cities in countries around the world.

\section{Conclusions}

The proliferation of Internet-based technologies has greatly reduced disruptions in collaborative prevention efforts during this perilous time, and the Foundation's SteerCos have capitalized on these platforms to continue their activities [13]. The activities of the Foundation and its SteerCo affiliates since the advent of the pandemic have suggested a number of steps that prevention professionals might consider in response, besides simply halting the implementation of strategies that depend on in-person contacts and, as feasible, adapting others for online delivery. These include continuing to engage with local governmental authorities as well as planning bodies (such as the community coalitions represented here as SteerCos). Finally, the SteerCos have illustrated a number of ways that engagement may be maintained with the workforce responsible for prevention-related activities, which includes health care workers and law enforcement, and how the visibility and reputation of these coalitions may be enhanced by providing health and nutritional packages to the most vulnerable members of the community.

\section{List Of Acronyms}




\begin{tabular}{ll} 
AB InBev & Anheuser-Busch InBev \\
\hline BAC & blood alcohol concentration \\
\hline COVID-19 & coronavirus disease 2019 \\
\hline DUI & driving under the influence \\
\hline E-SBI & electronic screening and brief intervention \\
\hline GP & general practitioner \\
\hline GSDG & Global Smart Drinking Goals \\
\hline NGO & non-governmental organization \\
\hline PPE & personal protective equipment \\
\hline SBI & screenings and brief interventions \\
\hline SBIRT & screening, brief intervention, and referral to drug treatment \\
\hline SteerCo & steering committee \\
\hline WHO & World Health Organization
\end{tabular}

\section{Declarations}

\section{Ethics Approval}

Our study was reviewed and approved by the Institutional Review Board (IRB) of Pacific Institute for Research and Evaluation (FWA00003078). We requested and received an exemption for our key informant interviews in reference to 45 CFR 46.101(b)(2).

\section{Consent to Participate}

Data collection included a description of programmatic work at the City Pilots and efforts to address the emerging COVID-19 implications within the context of their daily work. We also scanned publicly available media. Therefore, this effort was exempted by our IRB and consent was not necessary.

\section{Consent for Publication}

N/A

\section{Availability of Data and Materials}

The data that support the findings of this study are available from HBSA, but some restrictions apply to the availability of these data, which are proprietary for the current study, and so are not publicly available. Data are, however, available from the authors upon reasonable request and with permission of the $A B$ InBev Foundation.

\section{Competing Interests}

The authors have been supported within the past three years by funding from the alcohol industry to evaluate industry-sponsored programs to reduce harmful alcohol use.

\section{Funding}

The authors have been supported within the past three years by funding from the alcohol industry to evaluate industry-sponsored programs to reduce harmful alcohol use.

\section{Authors' Contributions}

1. P. S-R collected and analyzed the data regarding the impact of the COVID-19 pandemic on the City Pilots and contributed to the writing of this manuscript. L. L-G also analyzed data and contributed to the writing of this manuscript. D.A. F. contributed to the writing of this document and 
provided editorial support. C. L. R. provided oversight and contributed to the writing and editing of this manuscript. All authors read and approved the final manuscript.

\section{Acknowledgments}

This research and preparation of this manuscript were supported by funding from the $A B$ InBev Foundation. The content is solely the responsibility of the authors and does not necessarily represent the views of the $A B$ InBev Foundation, $A B$ InBev, or any of their affiliates. By contract, the authors had complete independence to determine the contents of this manuscript. The authors thank the Program Officers of the AB InBev Foundation and the Site Monitors of the City Pilots for the information they supplied.

\section{References}

1. Nurin T. During self-isolation, more people show online interest in alcohol than healthcare. Forbes. 2020 April 11.

2. Troianovski A. In pandemic's grip, Russia sees spike in age-old bane: Drinking. The New York Times. 2020 April 15.

3. Taub A. A new Covid-19 crisis: Domestic abuse rises worldwide. The New York Times. 2020 April 14.

4. Chutel L. Taking on Covid-19, South Africa goes after cigarettes and booze, too. The New York Times. 2020 May 17.

5. World Health Organization. Alcohol does not protect against COVID-19; access should be restricted during lockdown. World Health Organization; 2020 [cited 2020 April 14]; Available from: http://www.euro.who.int/en/health-topics/disease-prevention/alcoholuse/news/news/2020/04/alcohol-does-not-protect-against-covid-19-access-should-be-restricted-during-lockdown.

6. Mäkelä P, Österberg E. Upward trends in alcohol consumption and related harm in Finland. Nord Stud Alcohol Dr. 2007; 24(1_suppl):29-46.

7. Leon GR. Overview of the psychosocial impact of disasters. Prehosp Disaster Med. 2004; 19(1):4-9.

8. Boscarino JA, Adams RE, Galea S. Alcohol use in New York after the terrorist attacks: A study of the effects of psychological trauma on drinking behavior. Addict Behav. 2006; 31(4):606-21.

9. Vlahov D, Galea S, Ahern J, Resnick H, Boscarino JA, Gold J, et al. Consumption of cigarettes, alcohol, and marijuana among New York City residents six months after the September 11 terrorist attacks. Am J Drug Alcohol Ab. 2004; 30(2):385-407.

10. Cerdá $\mathrm{M}$, Tracy M, Galea S. A prospective population based study of changes in alcohol use and binge drinking after a mass traumatic event. Drug Alcohol Depen. 2011; 115(1-2):1-8.

11. North CS, Ringwalt CL, Downs D, Derzon J, Galvin D. Postdisaster course of alcohol use disorders in systematically studied survivors of 10 disasters. Arch Gen Psychiat. 2011; 68(2):173-80.

12. Chodkiewicz J, Talarowska M, Miniszewska J, Nawrocka N, Bilinski P. Alcohol Consumption Reported during the COVID-19 Pandemic: The Initial Stage. Int J Environ Res Public Health. 2020; 17(13):4677.

13. Carnevale Associates LLC. Policy Brief: Substance use prevention during the COVID-19 pandemic. 2020 [May]; Available from: https://www.carnevaleassociates.com/our-work/substance-use-prevention-during-the-covid-19-pandemic.html.

14. Campbell AM. An increasing risk of family violence during the Covid-19 pandemic: Strengthening community collaborations to save lives. Forensic Science International: Reports. 2020:100089.

15. Boserup B, McKenney M, Elkbuli A. Alarming trends in US domestic violence during the COVID-19 pandemic. Am J Emerg Med. 2020.

16. Rohrbach LA, Graham JW, Hansen WB, Flay BR, Johnson CA. Evaluation of resistance skills training using multitrait-multimethod role play skill assessments. Health Educ Res. 1987; 2(4):401-7.

17. Stockwell T. Responsible alcohol service: Lessons from evaluations of server training and policing initiatives. Drug Alcohol Rev. 2001; 20(3):25765.

18. Babor TF, Higgins-Biddle JC. Alcohol screening and brief intervention: Dissemination strategies for medical practice and public health. Addict. 2000; 95(5):677-86.

19. AB InBev. AB InBev Foundation: Reducing harmful drinking globally. 2020 [cited 2020 August 5]; Available from: https://www.ab-inbev.com/whatwe-do/smart-drinking/ab-inbev-foundation.html

20. AB InBev. Smart drinking goals: Making a tangible contribution. 2020 [cited 2020 August 5]; Available from: https://www.ab-inbev.com/what-wedo/smart-drinking/smart-drinking-goals.html.

21. Gandra A. Aumento do consumo de álcool preocupa no período de confinamento [Increase in alcohol consumption worries in the confinement period]. Agência Brasil; 2020 [April 21]; Available from: https://agenciabrasil.ebc.com.br/saude/noticia/2020-04/aumento-do-consumo-de-alcoolpreocupa-no-periodo-de-confinamento.

22. World Health Organization. O álcool e a COVID-19: o que você precisa saber [Alcohol and COVID-19: What you need to know]. World Health Organization; 2020 [April]; Available from: https://www.uniad.org.br/wpcontent/uploads/dlm_uploads/2020/04/PT_ALC_COVID_LONG_SHEET_114200PAS.pdf. 
23. Agência Brasil. Maior consumo de álcool durante confinamento eleva risco de alcoolismo e violência doméstica [Increased alcohol consumption during confinement increases risk of alcoholism and domestic violence]. HuffPost; 2020 [April 21]; Available from:

https://www.huffpostbrasil.com/entry/alcool-quarentena_br_5e9f1e51c5b6a486d07fe328.

24. Sigal L, Ramos Miranda NA, Martinez Al, Machicao M. 'Another pandemic': In Latin America, domestic abuse rises amid lockdown. Reuters; 2020 [April 27]; Available from: https://www.reuters.com/article/us-health-coronavirus-latam-domesticviol/another-pandemic-in-latin-americadomestic-abuse-rises-amid-lockdown-idUSKCN2291JS.

25. Ludlow R, Narciso D. Columbus Public Health refers bar distancing violations to prosecutor as DeWine vows enforcement. The Columbus Dispatch. 2020 May 16.

26. Taylor M. Help available for domestic violence victims during coronavirus shutdown. NBC4; 2020 [March 30]; Available from: https://www.nbc4i.com/community/health/coronavirus/help-available-for-domestic-violence-victims-during-coronavirus-shutdown/.

27. eNCA. SA Lockdown: Gauteng Liquor Forum calls for lifting of alcohol sales. 2020 [April 14]; Available from: https://www.youtube.com/watch? $v=$ sSOIVIDMTh0\&feature=youtu.be.

28. Whittles C. Impact of banning alcohol and tobacco. eTV; 2020 [March 31]; Available from: https://www.etv.co.za/news/impact-banning-alcoholand-tobacco.

29. de Wet P. If your surname starts with N or later, you may have to wait an extra day to buy booze. Business Insider; 2020 [May 14]; Available from: https://www.businessinsider.co.za/liquor-retailer-plan-to-limit-sales-when-alcohol-trade-is-legal-again-2020-5.

30. Pijoos I. Northern Cape couple who died of home-brewed beer loved each other dearly. Hearld Live; 2020 [May 7]; Available from: https://www.heraldlive.co.za/news/2020-05-07-northern-cape-couple-who-died-of-home-brewed-beer-loved-each-other-dearly/.

31. Ngqakamba S. Lockdown booze frenzy: Shoppers fill up carts so they don't go off their trolleys. News24; 2020 [March 26]; Available from: https://www.news24.com/SouthAfrica/News/lockdown-booze-frenzy-shoppers-fill-up-carts-so-they-dont-go-off-their-trolleys-20200326.

32. Nkanjeni U. 'His hatred for alcohol is too personal': SA weighs in on Cele's alcohol ban extension comments. DispatchLIVE; 2020 [April 7]; Available from: https://www.dispatchlive.co.za/news/2020-04-07-his-hatred-for-alcohol-is-too-personal-sa-weighs-in-on-celes-alcohol-banextension-comments/.

33. Isaacs L. Groote Schuur: Two-thirds drop in trauma cases due to lockdown's booze ban. Eyewitness News; 2020; Available from: https://ewn.co.za/2020/04/08/groote-schuur-two-thirds-drop-in-trauma-cases-due-to-lockdown-s-booze-ban.

34. Magubane T. Sharp rise in GBV cases during lockdown. IOL; 2020 [April 8]; Available from: https://www.iol.co.za/mercury/news/sharp-rise-ingbv-cases-during-lockdown-46433063.

35. Mabuza E. Regulation of liquor must be discussed after lockdown, says David Makhura. Times LIVE; 2020 [April 14]; Available from: https://www.timeslive.co.za/politics/2020-04-14-regulation-of-liquor-must-be-discussed-after-lockdown-says-david-makhura/.

36. Mertens B. Parket neemt vrachtwagen in beslag: Bestuurder zonder rijbewijs onder invloed van alcohol [Parquet confiscates truck: Driver without a license under the influence of alcohol]. HLN; 2020 [March 22]; Available from: https://www.hln.be/in-de-buurt/leuven/parket-neemtvrachtwagen-in-beslag-bestuurder-zonder-rijbewijs-onder-invloed-van-alcohol a71bc50a/.

37. Agren D. 'There's absolutely nothing': Locked-down Mexico grapples with national beer shortage The Guardian. 2020.

38. Castaneda D. Multaran a repartidores que trasladen bebidas alcoholicas a domicilios [Dealers who transfer alcoholic beverages to homes will be fined]. Zacatecas en Imagen; 2020 [April 19]; Available from: https://imagenzac.com.mx/capital/multaran-a-repartidores-que-trasladen-bebidasalcoholicas-a-domicilios/.

39. Agencia EFE. Mueren más de 100 por alcohol adulterado en Jalisco, Morelos, Puebla y Yucatán [More than 100 die of adulterated alcohol in Jalisco, Morelos, Puebla and Yucatan]. El Popular; 2020 [May 19]; Available from: https://www.elpopular.mx/2020/05/13/nacional/mueren-masde-100-por-alcohol-adulterado-en-jalisco-morelos-puebla-y-yucatan.

40. de Santiago C. DPSV ha recibido reportes de personas bebiendo alcohol en la alameda a bordo de vehículos [DPSV has received reports of people drinking alcohol in the mall on board vehicles]. Pagina 24; 2020 [April 14]; Available from:

https://pagina24zacatecas.com.mx/2020/04/14/local/dpsv-ha-recibido-reportes-de-personas-bebiendo-alcohol-en-la-alameda-a-bordo-devehiculos/.

41. Gobierno del Estado de Zacatecas. Aplicarán autoridades sanción máxima a quienes consuman alcohol en vehículos [Authorities will apply maximum sanction to those who consume alcohol in vehicles]. 2020; Available from: https://www.zacatecas.gob.mx/aplicaran-autoridadessancion-maxima-a-quienes-consuman-alcohol-en-vehiculos/.

42. Román H. Grupo Modelo donará gel antibacterial a Fundación IMSS [Grupo Modelo to donate antibacterial gel to IMSS Foundation]. El Sol de Zacatecas. 2020.

43. Oppenheim M. Mexico sees almost 1,000 women murdered in three months as domestic abuse concerns rise amid coronavirus. Independent. 2020 April 28.

44. Kurmanaev A, Andreoni M, Casado L, Taj M. Latin America's outbreaks now rival Europe's. But its options are worse. The New York Times. 2020 May 12.

Page $11 / 12$ 
45. Afición Política. Fundación AB InBev dona equipo de protección personal para médicos de hospitales en Zacatecas, conforme se acerca el pico de la pandemia por coronavirus [AB InBev Foundation donates personal protective equipment to hospital doctors in Zacatecas as the coronavirus pandemic peaks]. 2020 [cited 2020 August 6]; Available from: http://aficionzac.com/fundacion-ab-inbev-dona-equipo-de-proteccionpersonal-para-medicos-de-hospitales-en-zacatecas-conforme-se-acerca-el-pico-de-la-pandemia-por-coronavirus/? fbclid=IwAR1sDUOWR_E_8LC7bfRjxCKvlYGYHcAssFdkFYojl66-aE42oHp1C6JS3KQ.

46. Bendtsen $\mathrm{P}$, Johansson $\mathrm{K}$, Akerlind I. Feasibility of an email-based electronic screening and brief intervention (e-SBI) to college students in Sweden. Addict Behav. 2006; 31(5):777-87.

47. Woodall WG, Starling R, Saltz RF, Buller DB, Stanghetta P. Results of a randomized trial of web-based retail onsite responsible beverage service training: WayToServe. J Stud Alcohol Drugs. 2018; 79(5):672-9.

48. Steiner J, Woodall WG, Yeagley JA, Venegas M. The E-Chug: A randomized, controlled study of a web-based binge drinking intervention with college freshman. 2005.Available from: https://web.3rdmil.com/assets/guides/research/Steiner\%20-

\%20The\%20EChug\%20A\%20Randomized\%20Controlled\%20Study\%20of\%20\%20a\%20Web\%20Based\%20Binge\%20Drinking\%20Intervention.pdf.

\section{Supplementary Files}

This is a list of supplementary files associated with this preprint. Click to download.

- SupplementalFileCOVIDrelatedquestions.docx 